\section{Multiplanar Cyclohexane Rings}

IN 1931 I published a paper in the Journal of the Indian Chemical Society in which the four isomeric modifications of 4-methyl cyclohexane-1-carboxy-1acetic acid were described ${ }^{1}$. In a recent publication S. Goldschmidt and G. Grafinger ${ }^{2}$ observed that they could not isolate the acid $B$, as described above, and consequently they concluded that actually 4-methyl cyclohexane-1-carboxy-1-acetic acid existed in only two modifications, one melting at $137^{\circ}$ and the other at $174^{\circ}$. It appeared to me rather strange that the work, which was repeated a number of times before publication, should be altogether wrong. It was, therefore, considered desirable to get the work repeated once more in my presence, and this has accordingly been done now by a student of mine, Mr. Asutosh Mukherji, with the result that we found no difficulty whatever in isolating all the four modifications of the acid as described before. It may, however, be recorded here that the solubility of the ammonium salt of the acids $A, B$ and $C$ in absolute alcohol is as follows :

One gm. of acid $A$ dissolves in 75 c.c. of boiling absolute alcohol. ", " " " "

The quantity of the absolute alcohol must, therefore, be carefully regulated, otherwise, if acids $B$ and $C$ come out together in alcoholic solution, it becomes very difficult to separate them from one another. Regarding the suggestion of Goldschmidt that the acid $B$ may be a eutectic mixture of acids $A$ and $C$, it appears to be untenable and not based on experimental evidence. The mixture of the acids $A$ and $C$ gave at no time any sharply melting substance which would melt at $129^{\circ}$ or near about it as the acid $B$ does. The same is true for the acid $D$ also. It is difficult to say whether it is the unsuitable method of separation adopted by the German chemists that is responsible for their failure to get the acid $B$ and $D$. It may incidentally be mentioned that these isomers are not at all similar to any of those isolated from the para or ortho methyl cyclohexanone. Although all the expected isomeric acids from these latter ketones have not yet been isolated, the work so far completed will be published very shortly elsewhere.

The $p$-methyl cyclohexanone and other ketones of the series are now being prepared with different catalysts in order to see if the quality of the ketones has anything to do with the formation of the isomeric acids.

\section{Presidency College, Calcutta. \\ June 28. \\ ${ }^{2}$ See NATCRE, 127, 253; 1931. \\ 2 Ber., 68, 279. \\ M. QUdRat-I-KHUdA.}

\section{Vapour Pressure of Hexadeuterobenzene}

IT has recently been recorded ${ }^{x}$ that the vapour pressure of deuterium iodide is slightly, but definitely, greater than that of protium iodide, a behaviour qualitatively analogous to that exhibited by the two hydrogen fluorides ${ }^{2}$. This type of anomaly is, therefore, not confined to substances which are generally recognised as associated in the vapour state $^{3}$.

We know an even elearer example: the vapour pressure of $\mathrm{C}_{6} \mathrm{D}_{6}$ is greater than that of $\mathrm{C}_{6} \mathrm{H}_{6}$ for the whole temperature range $0^{\circ}-80^{\circ} \mathrm{C}$. (below the freezing point, $6 \cdot 8^{\circ}$, the liquid is supercooled) over which we have measured it. The boiling point of $\mathrm{C}_{6} \mathrm{D}_{6}$ at normal pressure is $0.8^{\circ}$ lower than that of $\mathrm{C}_{6} \mathrm{H}_{6}$, contrary to a recent claim that the former is higher ${ }^{4}$.

University College,

C. L. Wilson.

London.

July 29.

${ }^{1}$ Bates, Halford and Anderson, J. Chem. Phys., 3, 415; 1935. 2 Claussen and Hildebrand, J. Amer. Chem. Soc., 56, $1820 ; 1934$ ${ }^{3}$ Lewis and Schutz, ibid., p. 493. Wilson, J. Chem. Soc., 492: 1935. C Clemo and McQuillen, J. Chem. Soc., 851; 1935.

\section{Inverse Probability}

IN my letter ${ }^{1}$ of May 4, I was not defending Eddington's solution of his problem in inverse probability, but was attacking Dr. Dingle's diseussion $^{2}$ of his own simplified problem : If $A$ and $D$ each speak the truth once in three times independently, and $A$ says that $D$ lies, what is the probability that $D$ speaks the truth? In his discussion Dr. Dingle said, "Sir Arthur's treatment effectively combines the knowledge of $D$ 's moral character with that of $A$ 's. But is it not clear that such combination is purely fictitious? From our knowledge of $D$ the probability is $\frac{1}{3}$; from our (independent) knowledge of $A$ it is $\frac{2}{3}$. The results are inconsistent because the data are independent; we are effectively defining probability in different ways". It should be clear from my solution of Dr. Dingle's problem that the answer is neither $\frac{1}{3}$ nor $\frac{2}{3}$, but $\frac{1}{2}$, and nothing else. There are really no inconsistencies, as I showed by drawing up the association table.

I do not agree with Dr. Dingle's more recent ${ }^{1}$ assertion, that one must ". . . either $(a)$ define probability in a purely mathematical way and so obtain a unique solution which may be both consistent and correct ...., or $(b)$ refrain from calling meaningless mathematical functions 'probability', and then obtain two solutions to each problem". My treatment used "probability" in the simplest and perhaps most significant meaning of the word. Out of $4 N / 9$ cases where $A$ says that $D$ lies, $D$ actually lies $2 N / 9$ times and tells the truth $2 N / 9$ times. Does Dr. Dingle seriously maintain that the ratio, $2 N / 9 \div 4 N / 9=\frac{1}{2}$, is a "meaningless mathematical function", or that, given that our case is one of these $4 N / 9$ cases, there is any lack of significance in saying that the probability that $D$ tells the truth is $\frac{1}{2}$ ?

Although I cannot subscribe to Dr. Dingle's arguments, I am inclined to agree with him that Eddington's solution was incorrect. The data supplied by Eddington do not seem to me to be sufficient to allow one to write down the class frequencies in a contingency table.

Harvard College Observatory, Cambridge, Mass. July 11.

1 NAture, 135, 1073; 1935.

2 Nature, 135, 451; 1935.

The point at issue between Dr. Sterne and myself is ultimately whether consistency is equivalent to significance or not. Evidently it is not easy to clear it up in a few sentences, and the Editor has invited me to write an article on the whole question of probability which will appear in NATURE shortly. 